\title{
A percepção dos gestores sobre as práticas do modelo de gestão e do processo de gestão: um estudo em uma empresa varejista brasileira
}

\author{
Claudio Parisi
}

Doutorado em Controladoria e Contabilidade pela Universidade de São Paulo - USP Professor da Fundação Escola de Comércio Álvares Penteado - FECAP Av. Liberdade, 532. São Paulo/SP

E-mail: claudio.parisi@uol.com.br

Maria de Gracia Lopez Martin Fundação Escola de Comércio Álvares Penteado - FECAP Av. Liberdade, 532. Liberdade. São Paulo/SP

E-mail: gracialopez@ig.com.br

Evandir Megliorini Doutorado em Ciências Contábeis pela FEA-USP Av. Prof. Luciano Gualberto, 908. São Paulo/SP. CEP: 05508-010

E-mail: evandir.megliorini@ufabc.edu.br

\begin{abstract}
Auster Moreira Nascimento Doutorado em Controladoria e Contabilidade pela Universidade de São Paulo - USP Fundação Escola de Comércio Álvares Penteado - FECAP E-mail: auster@uol.com.br
\end{abstract}

\section{RESUMO}

O atual cenário de competitividade dos negócios requer dos gestores que estes gerenciem os recursos eficientemente para alcançar os objetivos de suas organizações. Nesse ambiente, um processo decisório descentralizado, no qual os gestores adotem uma postura empreendedora, assumindo o papel de "donos do empreendimento" das áreas sob suas responsabilidades, pode ser um aspecto decisivo para a obtenção de resultados satisfatórios. Isso se contrapõe a um estilo de gestão tradicional, caracterizado por uma administração centralizada, que possivelmente tornem 0 processo decisório não apropriado para um ambiente dinâmico de negócios, no qual a velocidade na tomada de decisão se torna um aspecto relevante para o alcance do bom desempenho empresarial. O objetivo desse artigo foi o de conhecer se as percepções dos gestores integrantes do grupo de planejamento sobre as práticas de gestão envolvendo o modelo de gestão e o processo de gestão são aderentes aos preceitos abordados na literatura existente sobre esse tema e que foi usada no suporte à teorização durante a fase de implantação da solução. Do ponto de vista metodológico, trata-se de uma pesquisa descritiva e quantitativa, desenvolvida com apoio de questionário respondido por gestores entrevistados. Os dados obtidos foram tratados com o uso de estatística descritiva. Os resultados apontam para a aderência parcial das 
A percepção dos gestores sobre as práticas do modelo de gestão e do processo de gestão: um estudo em uma empresa varejista brasileira Claudio Parisi, Maria de Gracia Lopez Martin, Evandir Megliorini, Auster Moreira Nascimento

práticas do modelo de gestão e do processo de gestão existentes na empresa em relação aos preceitos preconizados na literatura.

Palavras Chaves: Varejo. Modelo de Gestão. Processo de Gestão.

\section{Managers' perception of the management model practices and of the management process: a study at a Brazilian retail firm}

\section{ABSTRACT}

The current scenario of business competitiveness requires managers to manage resources efficiently to achieve the goals of their organizations. In this environment, a decentralized decision-making process, in which managers adopt an enterprising attitude, taking on the role of "owners of the venture" of the areas under their responsibility, can be a decisive aspect for the obtainment of satisfactory results. This counteracts a traditional management style, characterized by centralized administration, which may make the decision-making process inappropriate for a dynamic business environment in which speed in making decisions becomes a material aspect for achieving good business performance. This article was aimed at finding out whether the perceptions of managers from the planning group in relation to management practices involving the management model and the management process are adherent to the precepts addressed in the existing literature on this subject and that was used to support the theorization during the solution implementation phase. From the methodological point of view, it is a descriptive and quantitative survey, using a questionnaire answered by managers. The data obtained was processed using descriptive statistics. The results indicate partial adherence of the management model practices and of the management process existing at the company in relation to the precepts advocated in literature.

Key Words: Retail. Management Model. Management Process.

\section{INTRODUÇÃO}

O varejo brasileiro recentemente tem passado por mudanças que thes alteram o perfil até então existente, tais como: tendências de consolidação em alguns de seus segmentos; importação de produtos antes comprados localmente; pressão sobre as margens de lucro das empresas do setor causada pela existência de oligopólios industriais, entre outras. Num entendimento preliminar sobre as condições de organização e desenvolvimento das empresas do setor, Costa e Garcia (2006, p. 63) afirmam que: 
A percepção dos gestores sobre as práticas do modelo de gestão e do processo de gestão: um estudo em uma empresa varejista brasileira

Claudio Parisi, Maria de Gracia Lopez Martin, Evandir Megliorini, Auster Moreira Nascimento

a atividade varejista integra funções como a procura, seleção, aquisição, distribuição, comercialização e entrega dos produtos. Algumas lojas estendem suas atividades à assistência técnica, designada em anos recentes, como "serviço pós-venda". A mudança nas atribuições do setor varejista está relacionada à estratégia das empresas de ampliar sua participação no mercado.

Manãs e Pacanhan (2004, p. 22) ressaltam a importância do varejo como uma atividade setorial do ponto de vista econômico, estratégico e social, afirmando que:

sob o aspecto econômico, o varejo fomenta a arrecadação fiscal, movimenta as economias regionais e gera investimentos. No plano social, contribui para a geração de empregos e manutenção de diversas fontes de sustentação familiar. No plano estratégico a contribuição do escopo varejista está intimamente relacionada ao seu papel de conexão entre o fabricante e o consumidor, através da oferta variada de produtos e de suas distintas formatações e tipologias específicas para cada mercado.

No Brasil, o processo de abertura de mercado e o controle da inflação, no início dos anos 1990, afetaram não só apenas as indústrias de transformação, mas, também, o segmento varejista. Grandes redes deste setor que operam em escala mundial, têm direcionado seus investimentos para os países de economia emergente, como o Brasil, fazendo aumentar a intensidade da concorrência.

A combinação do aumento da concorrência, da diversificação da oferta de novos produtos, aliada a uma legislação que protege os consumidores, acabou por moldar clientes conscientes sobre os seus direitos tornando-se, com isso, cada vez mais exigentes. Isso fez com que o varejo passasse por uma espécie de revolução, na qual a gestão amadora cedeu espaço para a profissional como meio de captar e manter clientes.

Em um ambiente competitivo, os gestores precisam gerenciar os recursos eficientemente para alcançarem os objetivos de suas organizações. Nesse contexto, a partir dos princípios de administração do negócio definidos no modelo de gestão, faz-se necessário um processo estruturado de gestão, materializando o processo de tomada 
A percepção dos gestores sobre as práticas do modelo de gestão e do processo de gestão: um estudo em uma empresa varejista brasileira Claudio Parisi, Maria de Gracia Lopez Martin, Evandir Megliorini, Auster Moreira Nascimento

de decisões da empresa, que conduza a empresa à situação por ela objetivada (CATELLI; PEREIRA; VASCONCELOS; 1999).

A organização objeto dessa pesquisa, visando à adequação de sua administração à realidade competitiva do setor do qual é parte integrante, promoveu mudanças em seu modelo de gestão e processo de gestão. Nesse sentido, o objetivo desse trabalho é o de conhecer se as percepções dos gestores integrantes do grupo de planejamento sobre as práticas de gestão envolvendo o modelo de gestão e o processo de gestão são aderentes aos preceitos abordados na literatura existente sobre esse tema e que foi usada no suporte à teorização durante a fase de implantação da solução.

Diante do exposto, evidencia-se o seguinte problema de pesquisa para este estudo: Segundo a percepção dos gestores, as práticas decorrentes do modelo de gestão e do processo de gestão implantados pela empresa varejista são aderentes aos preceitos conceituados na literatura?

Este estudo se justifica pela necessidade continua de renovação do conhecimento do alinhamento conceitual entre academia e empiria no que se refere às práticas de gestão adotadas pelas organizações. A empresa utilizada como referência é uma empresa varejista sediada no interior do estado do Rio Grande do Sul, líder nesse segmento na região em que atua. Trata-se de um caso de uma organização que buscou integrar conceitos de gestão econômica aos do balanced scorecard para resolver o seu problema de gestão de desempenho, com ênfase à gestão do crescimento dada sua pretensão de rápida expansão.

Destaque-se que o foco da pesquisa bibliográfica realizada se deu de acordo com duas abordagens, ambas consideradas relevantes para o desenvolvimento do estudo de caso, a saber: gestão econômica e balanced scorecard. Isso se justifica devido a empresa estudada ter desenvolvido o seu projeto de mudanças em seu modelo de gestão, bem como em seu processo de gestão, tendo essas duas vertentes teóricas. Portanto, o instrumento de pesquisa foi desenvolvido especificamente para esse contexto, ou seja, voltado a investigar a prática de conceitos de gestão econômica 
A percepção dos gestores sobre as práticas do modelo de gestão e do processo de gestão: um estudo em uma empresa varejista brasileira Claudio Parisi, Maria de Gracia Lopez Martin, Evandir Megliorini, Auster Moreira Nascimento

e do BSC relacionados à definição do modelo de gestão e estruturação do processo de gestão sob essas duas perspectivas.

Por fim, a pesquisa não teve como escopo investigar o grau de institucionalização desses instrumentos de gestão e nem analisar criticamente o modelo conceitual do projeto proposto para empresa. Limitou-se, portanto, à percepção dos gestores participantes do estudo.

\section{FUNDAMENTAÇÃO TEÓRICA}

\subsection{0 mercado varejista brasileiro}

O varejo consiste em todas as atividades que englobam o processo de venda de produtos e serviços para atender às necessidades dos consumidores. Sobre isso, Kotler (2000, p. 540) afirma que "o varejo inclui todas as atividades relativas à venda de produtos ou serviços diretamente aos consumidores finais, para uso pessoal e não comercial".

Os varejistas originariamente nacionais, ao mesmo tempo em que expandem as suas operações, sofrem a concorrência de grandes grupos internacionais, como decorrência do processo de globalização. Comerciantes que não conseguem evoluir na velocidade requerida pelo mercado são absorvidos por concorrentes mais estruturados (PARENTE, 2000).

Nesse contexto, o Brasil representa uma oportunidade de mercado, oferecendo perspectivas de crescimento para um grande número de operações de empresas do varejo, que para cá se deslocam, trazendo capital, tecnologia e novas modalidades de comercialização (GIULIANI, 2004).

O Instituto para o Desenvolvimento do Varejo - IDV (2008) apresenta dados que confirmam esse cenário de crescimento, conforme pode ser apreciado no gráfico 1 , apresentado a seguir. 
A percepção dos gestores sobre as práticas do modelo de gestão e do processo de gestão: um estudo em uma empresa varejista brasileira Claudio Parisi, Maria de Gracia Lopez Martin, Evandir Megliorini, Auster Moreira Nascimento

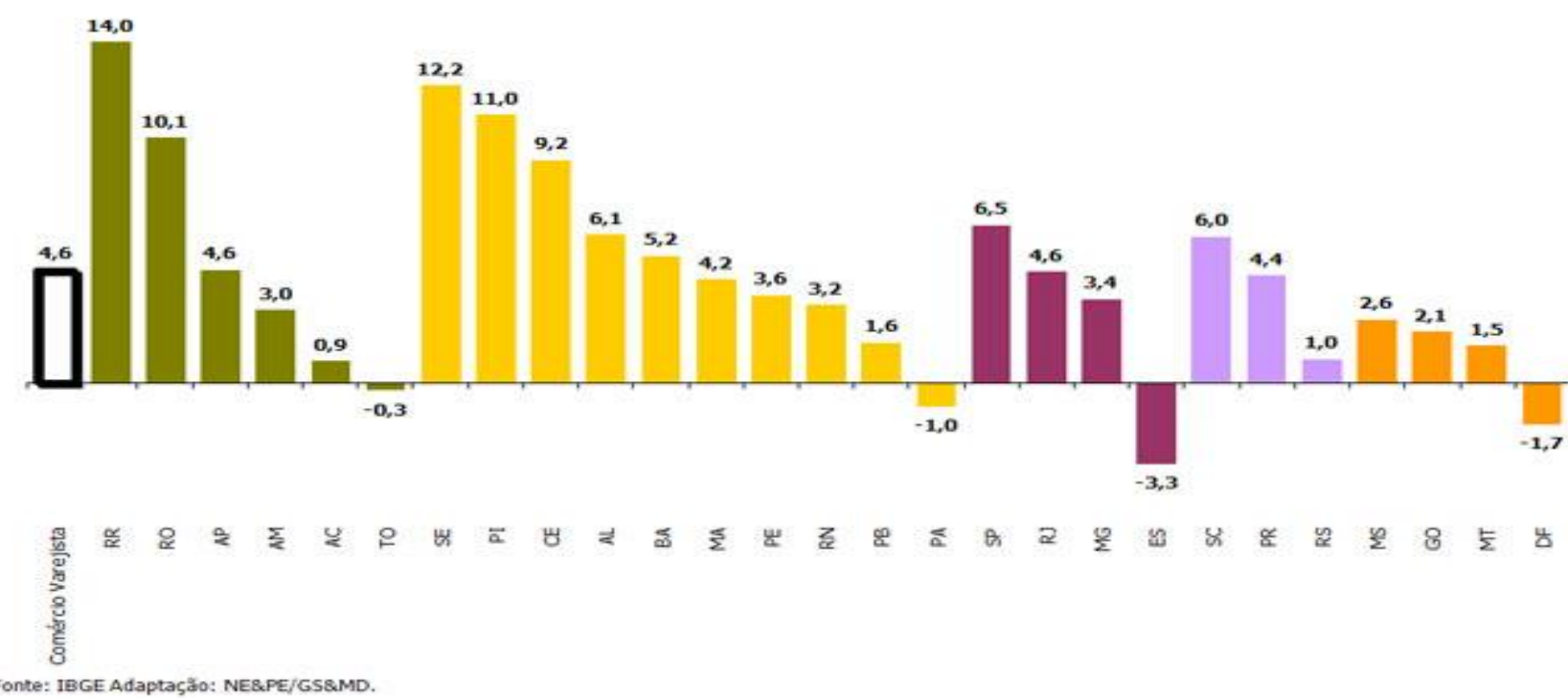

Gráfico 1 - Evolução do varejo brasileiro e regional (setembro/2007 a setembro/2008) Fonte: IDV (2008).

Os percentuais apresentados no gráfico 1 reforçam a importância da evolução do varejo brasileiro e dos estudos devotados à análise do comportamento do desempenho da gestão nesse segmento.

\subsection{Modelo de Gestão e Processo de Gestão}

Para efeito desse estudo, focou-se principalmente nas contribuições geradas pelos pesquisadores de Controladoria no Brasil sobre o tema em questão. Conforme Nakagawa (2003, p. 37), o "modelo de gestão consubstancia-se no conjunto de crenças e valores da empresa, fortemente influenciado pelas crenças e valores dos principais executivos, particularmente de seus proprietários e da alta administração".

Guerreiro (1989, p. 229) ao conceituar o modelo de gestão, afirma que os objetivos a serem observados por tal modelo devem assegurar: 
A percepção dos gestores sobre as práticas do modelo de gestão e do processo de gestão: um estudo em uma empresa varejista brasileira

Claudio Parisi, Maria de Gracia Lopez Martin, Evandir Megliorini, Auster Moreira Nascimento

- A redução de risco do empreendimento no cumprimento da missão e a garantia de que a empresa estará sempre buscando o melhor em todos os sentidos;

- O estabelecimento de uma estrutura de operações adequada que possibilite o suporte requerido para as suas atividades;

- A orientação geral dos esforços por meio de um estilo e de uma filosofia de trabalho que criem atividades construtivas;

- A adoção de um clima motivador e o engajamento de todos, principalmente dos gestores, em torno dos objetivos da empresa e de suas atividades;

- A aferição se a empresa está cumprindo sua missão ou não, se foi feito o que deveria ter sido em termos de produtos, recursos e esforços, e se o que não foi está sendo corrigido ou aperfeiçoado;

- O conhecimento do comportamento das variáveis relativas aos ambientes externo e interno e suas tendências, do resultado da avaliação dos planos alternativos de ação e das transações/eventos ocorridos em cada período e identificando onde "as coisas" aconteceram de maneira insatisfatória.

Por sua vez, Parisi (1999) contribui para o assunto apontando as diferenças entre o que chama de modelo de gestão tradicional e aquele proposto por Catelli (1999). Segundo esse autor, o modelo de gestão tradicional é centralizado, tornando o processo decisório não compatível com o atual ambiente de negócios, onde a velocidade e a agilidade na tomada de decisão passaram a ser valores relevantes para garantir o bom desempenho empresarial. Já para o sistema de gestão econômica proposto por Catelli (1999), o modelo de gestão é estruturado com base na descentralização do processo decisório, o que permite agilidade na tomada de decisão. O Quadro 1 apresenta as principais diferenças entre o modelo centralizado e descentralizado apontadas por Parisi (1999). 
A percepção dos gestores sobre as práticas do modelo de gestão e do processo de gestão: um estudo em uma empresa varejista brasileira

Claudio Parisi, Maria de Gracia Lopez Martin, Evandir Megliorini, Auster Moreira Nascimento

\begin{tabular}{|c|c|}
\hline $\begin{array}{c}\text { MODELO TRADICIONAL COM GESTÃO } \\
\text { CENTRALIZADA }\end{array}$ & $\begin{array}{c}\text { MODELO ECONÔMICO COM GESTÃO } \\
\text { DESCENTRALIZADA }\end{array}$ \\
\hline Processo decisório tende a ser centralizado & Processo decisório descentralizado \\
\hline $\begin{array}{l}\text { Funções decorrentes da estrutura } \\
\text { organizacional e responsabilidades não } \\
\text { claramente identificadas (áreas nebulosas) }\end{array}$ & $\begin{array}{l}\text { Funções e responsabilidades decorrentes da } \\
\text { missão (da empresa e da área específica do } \\
\text { gestor) }\end{array}$ \\
\hline $\begin{array}{l}\text { Autoridade decorrente da delegação } \\
\text { informal de poder }\end{array}$ & $\begin{array}{l}\text { Autoridade compatível com as funções e } \\
\text { responsabilidades }\end{array}$ \\
\hline $\begin{array}{l}\text { Estilo individualista (visão feudal das áreas } \\
\text { da empresa) }\end{array}$ & Estilo participativo (busca integração) \\
\hline Postura burocrática & Postura empreendedora (faz acontecer) \\
\hline $\begin{array}{l}\text { Papel de "tecnocrata" do empreendimento } \\
\text { sob sua responsabilidade }\end{array}$ & $\begin{array}{l}\text { Papel de "dono" do empreendimento sob sua } \\
\text { responsabilidade }\end{array}$ \\
\hline Processo de gestão centralizado & $\begin{array}{c}\text { Processo de gestão que abrange: planejamento } \\
\text { estratégico, planejamento operacional, execução } \\
\text { e controle; orientado à otimização do resultado } \\
\text { econômico }\end{array}$ \\
\hline $\begin{array}{c}\text { Avaliação de desempenho baseada em } \\
\text { indicadores da gestão operacional, tais } \\
\text { como: faturamento, saldo de caixa, custos, } \\
\text { volumes físicos, rejeição de peças } \\
\text { (qualidade), quantidade de devoluções, } \\
\text { níveis de estoque, satisfação do cliente, } \\
\text { benchmarking etc. }\end{array}$ & $\begin{array}{l}\text { Avaliação de desempenho baseada no } \\
\text { desempenho econômico }\end{array}$ \\
\hline
\end{tabular}

Quadro 1 - Modelos de gestão

Fonte: Adaptado de Parisi (1999).

Entre os aspectos que caracterizam o modelo de gestão econômica destaca-se a descentralização do processo decisório e o conseqüente estilo participativo. As funções e responsabilidades decorrentes das missões, tanto da empresa em si quanto de cada uma de suas áreas, se materializam em um processo de gestão que abrange planejamento estratégico, planejamento operacional, execução e controle, orientado à otimização do resultado econômico da empresa.

Esse modelo reconhece que a pressão imposta pelo ambiente de mercados competitivos pressupõe a necessidade de maior agilidade da empresa, no sentido de aproveitar as melhores oportunidades e amenizar as ameaças. É um modelo baseado na gestão por resultados. 
A percepção dos gestores sobre as práticas do modelo de gestão e do processo de gestão: um estudo em uma empresa varejista brasileira Claudio Parisi, Maria de Gracia Lopez Martin, Evandir Megliorini, Auster Moreira Nascimento

No que se refere especificamente ao processo de gestão, Nakagawa (2003, p. 27) afirma que se configura "com base no modelo de gestão da organização e, por isso, assume diversas formas na realidade das empresas".

Nesse contexto, o processo de gestão tem o papel de assegurar a dinâmica das decisões tomadas na empresa, conduzindo-a efetivamente ao cumprimento de sua missão (NAKAGAWA, 2003, p. 37). De acordo com Parisi (1999, p. 264), processo de gestão "é a expressão do objetivo da gestão".

Cruz (1991) define o processo de gestão como o processo de decisão, sendo baseado em um conjunto de conceitos e princípios coerentes entre si, que visam a garantir a consecução da missão da empresa. Ela, por sua vez, é tão importante que, na visão de Rossi Júnior (2004), todos os envolvidos na sua declaração devem se comprometer efetivamente com o futuro da organização.

A função da declaração da missão é fazer com que todos os diferentes grupos de interesse na organização foquem uma direção estratégica, conforme Rodriguez (2002). Dessa forma, o planejamento estratégico é a etapa do processo de gestão que define políticas, diretrizes e objetivos estratégicos, e que tem como produto final a busca do equilíbrio dinâmico das interações da empresa com as variáveis ambientais que a afetam.

Segundo Catelli et al. (1999, p. 284), para viabilizar essa fase, é necessário que haja

[...] clara definição da missão da empresa, o envolvimento e a participação dos gestores, o apoio de sistema de informações sobre variáveis ambientais, que gerem informações sobre os desempenhos passados e propiciem 0 conhecimento das variáveis atuais dos ambientes interno e externo.

Nakagawa (2003, p. 38) conclui que "dessa forma, o planejamento estratégico pode ser visto como uma técnica por meio da qual é determinada a atitude ou a posição estratégica da empresa" e, acrescenta que "para que a realização dessa fase seja possível, é necessário que haja a disseminação da real missão da empresa, bem como o envolvimento de todos os administradores e um eficiente sistema de informações". 
A percepção dos gestores sobre as práticas do modelo de gestão e do processo de gestão: um estudo em uma empresa varejista brasileira Claudio Parisi, Maria de Gracia Lopez Martin, Evandir Megliorini, Auster Moreira Nascimento

Nessa etapa, cabe à administração da empresa estabelecer os objetivos estratégicos, certificando-se de que estes estejam relacionados com a missão, e que sejam entendidos e compartilhados pelos grupos de interesse, que sejam realistas, e o mais específicos possíveis e, principalmente, factíveis.

Os objetivos estratégicos devem ser descritos de modo que possam ser compreendidos e utilizados pelos colaboradores. Como aponta Rossi Júnior (2004), os objetivos estratégicos são o resultado de uma dimensão mais geral pretendida pela organização, enquanto as metas de desempenho são mais concretas e objetivas, necessárias ao alcance de seus objetivos e que servem como uma referência para a avaliação do desempenho organizacional. Materializando essa abordagem, a proposta de Balanced Scorecard de Kaplan e Norton (1997), apresenta, além do sistema de avaliação dos objetivos estratégicos, a ênfase na importância de se propagar a visão estratégica da organização, ou seja, qual é sua ambição numa perspectiva de longo prazo para que todos possam alcançar os objetivos e metas definidas por sua administração.

Mediante a missão e os objetivos estabelecidos pela administração da empresa, os gestores devem se adequar à realidade percebida no dia-a-dia, analisando o cenário no entorno do negócio, planejando criteriosamente as suas metas e ações e implementando-as, a fim de assegurar que os objetivos organizacionais sejam alcançados, de acordo com Tatikonda e Tatikonda (1998) e Hacker e Brotherson (1998). Segue-se então a etapa de execução, definida por Catelli et al. (1999, p. 138) como a "fase em que os recursos são consumidos e os produtos gerados".

A fase de execução tem por finalidade, segundo Catelli et al. (1999), cumprir os objetivos estabelecidos no planejamento operacional de curto prazo, otimizando cada evento. Trata-se, portanto, de uma fase em que as ações são implementadas tendo como produto o surgimento de transações realizadas. Dessa forma, a fase da execução das atividades planejadas mostra-se de grande relevância, já que é pelas decisões sobre os eventos, nesta fase, que o resultado econômico está sendo gerado, de acordo com Nakagawa (2003). 
A percepção dos gestores sobre as práticas do modelo de gestão e do processo de gestão: um estudo em uma empresa varejista brasileira Claudio Parisi, Maria de Gracia Lopez Martin, Evandir Megliorini, Auster Moreira Nascimento

Segue-se a etapa do controle que, na visão de Catelli et al. (1999), tem por finalidade assegurar a efetiva realização dos resultados planejados, implementando ações corretivas quando os resultados realizados diferirem dos planejados. A função do controle, segundo Mosimann e Fisch (1999, p.70), "configura-se como um instrumento administrativo exigido pela crescente complexidade das empresas, a fim de se atingir um bom desempenho".

Para Catelli et al. (1999), esse processo consiste na identificação das transações realizadas, comparação dos resultados realizados com os planejados, identificação das causas dos desvios e na decisão sobre as ações a serem implementadas para se corrigirem tais desvios.

Com relação à proposta do Balanced Scorecard (BSC), Kaplan e Norton (1992) defendem que a gestão deve ser orientada por objetivos e para a implantação da estratégia de longo prazo da empresa, e o processo de planejamento (gestão) deve ser contínuo e formal. Da mesma forma que a proposta de gestão econômica, os criadores do BSC também defendem a descentralização como um dos atributos desejáveis para a gestão de desempenho de uma empresa. Infere-se que, quando do desdobramento do BSC da alta administração para as unidades organizacionais, os gestores deveriam ter autonomia e poder para tomar as ações necessárias para o alcance das metas estabelecidas para as suas áreas de atividades (KAPLAN; NORTON, 2006).

Outros autores abordam a integração do BSC com outros instrumentos de gestão (rolling forecast, planejamento estratégico etc.) na tentativa de melhor estruturar um processo de gestão mais amplo que atenda tanto a gestão da estratégia como a operacional (McNAIR; WATTS, 2009; JORGENSEN, 2002).

Por outro lado, existem controvérsias sobre se tais abordagens usadas na estruturação do processo de gestão trariam, de fato, melhoria de desempenho das organizações. DeBusk e Crabtree (2006, p. 44) apontam pesquisas sobre o uso do BSC cujos resultados são conflitantes. Com base em sua própria pesquisa, os autores concluíram que $66 \%$ das empresas usuárias do BSC que relacionam a sua política de remuneração de gestores às metas de desempenho definidas a partir do uso desse instrumento, tendem a reconhecer que ele contribuiu para melhoria do desempenho 
A percepção dos gestores sobre as práticas do modelo de gestão e do processo de gestão: um estudo em uma empresa varejista brasileira Claudio Parisi, Maria de Gracia Lopez Martin, Evandir Megliorini, Auster Moreira Nascimento

organizacional. Por outro lado, a percepção daqueles usuários de BSC que não o vinculam a remuneração variável a esse sistema de indicadores é de que ele não contribui explicitamente para tal melhoria.

Radnor e Barnes (2007, p. 393), traçando uma análise da evolução histórica sobre gestão de desempenho, afirmam que existem desafios ainda a serem solucionados para a efetiva gestão e mensuração de performance de uma organização. Dentre os desafios, os autores destacam a necessidade de se desenvolver um conjunto razoável e coerente de indicadores de desempenho para os processos envolvendo os negócios da organização, ao invés de uma proliferação destes para tarefas individuais e atividades operacionais. O BSC pode ter induzido as empresas a tal fenômeno de proliferação de indicadores. Especificamente, tratando da gestão operacional da organização, os autores concluem que não adianta medir desempenho se não existir de fato uma gestão desse desempenho.

\section{A PESQUISA}

\subsection{A Empresa objeto de pesquisa}

Para delimitar a abrangência da pesquisa, a presente análise está centrada em uma empresa de varejo situada no estado do Rio Grande do Sul, atuando no comércio de eletroeletrônicos, material de construção e móveis. Por exigência da empresa, a razão social da entidade foi omitida nesse estudo. A empresa objeto do estudo iniciou suas atividades em 1967 no interior do Rio Grande do Sul, como uma pequena empresa familiar de comércio e representações. Em 2008 empregava mais de 3.000 funcionários, distribuídos entre as mais de 161 lojas pertencentes à rede.

A partir de 2003 a empresa investiu em ferramentas gerenciais para estruturar e formalizar o seu processo de gestão, bem como na qualidade de suas lideranças e na profissionalização de seu quadro de funcionários. Desde os anos 1980, a empresa realiza o planejamento estratégico e, a partir de 2004, passou a implantar outros instrumentos para a estruturação do processo de gestão e seu respectivo suporte. Entre esses instrumentos destaca-se o Balanced Scorecard, o qual foi implantado para 
A percepção dos gestores sobre as práticas do modelo de gestão e do processo de gestão: um estudo em uma empresa varejista brasileira Claudio Parisi, Maria de Gracia Lopez Martin, Evandir Megliorini, Auster Moreira Nascimento

a gestão corporativa e teve o seu desdobramento para cada tipo de negócio e, mais analiticamente, por loja, buscando a descentralização do processo decisório e a formalização da avaliação de desempenho. No que se refere à Gestão Econômica, a sua proposta norteou as definições do modelo de gestão e também foram implantados instrumentos para a simulação e apuração do resultado econômico por loja, por negócio e a para o resultado consolidado da empresa. Em linha com a abordagem da Gestão Econômica, a empresa já usava desde o início dos anos 1990 um simulador de margem de contribuição para gestão de preços em suas lojas.

Contribuiu para o crescimento da empresa a aquisição de concorrentes, a implementação de seu próprio cartão de crédito, denominado private label, que é aceito, também, em mais de 12 mil estabelecimentos comerciais do interior gaúcho. A empresa atua, ainda, com a administração de consórcios. Mais da metade da receita do grupo, na ocasião desse estudo estimada em 600 milhões de reais, vinha da comercialização de materiais para construção.

\subsection{Métodos e técnicas de pesquisa}

Esta pesquisa é descritiva e quantitativa. Foi desenvolvido e aplicado um questionário como instrumento de coleta de dados, respondido em entrevista com gestores.

Concluída a fundamentação teórica, em março de 2008, iniciou-se a construção do questionário. Como apontam Hill e Hill (2002), a construção de um questionário equivale a traduzir os objetivos da pesquisa em questões específicas. A inserção das perguntas no questionário deve refletir cuidadosamente o objetivo geral, ou seja, o tipo de informação pretendida.

O contato com a empresa foi formalizado em 29 de setembro de 2008, por meio de uma carta dirigida à sua Administração Corporativa, que em outubro de 2008 aprovou a realização da pesquisa, ficando estabelecido o envio do questionário ao grupo de planejadores composto por 28 executivos, dois quais 3 eram diretores e 25 ocupavam cargos de gerentes e coordenadores. 


\section{A percepção dos gestores sobre as práticas do modelo de gestão e do processo de gestão: um estudo em uma empresa varejista brasileira Claudio Parisi, Maria de Gracia Lopez Martin, Evandir Megliorini, Auster Moreira Nascimento}

O questionário foi enviado aos 28 executivos pertencentes ao grupo de planejadores em 10 de outubro de 2008. Foram obtidas 16 respostas até o dia 3 de novembro de 2008 , data em que se deu por encerrada a pesquisa.

O questionário foi constituído de 14 assertivas com respostas de múltipla escolha, dispostas em uma escala do tipo Likert. Os respondentes indicaram se discordavam totalmente (1), discordavam (2), concordavam (3), concordavam plenamente (4). Além disso, os respondentes podiam declarar desconhecer ou não saber informar se tais assertivas se aplicavam à empresa. As respostas foram codificadas em valores de 1 a 4 graus máximos de discordância e de concordância.

No quadro 2 estão descritas as assertivas, variáveis-chave, objetivos e os autores da bibliografia consultada que inspiraram as suas formalizações.

\begin{tabular}{|c|c|c|c|c|}
\hline & Assertiva & $\begin{array}{l}\text { Variável- } \\
\text { chave }\end{array}$ & Objetivo & Fonte \\
\hline 1 & $\begin{array}{c}\text { A empresa trabalha de forma } \\
\text { interdependente para o alcance dos } \\
\text { seus objetivos }\end{array}$ & $\begin{array}{l}\text { Integração } \\
\text { entre as } \\
\text { áreas }\end{array}$ & $\begin{array}{l}\text { Verificar a aderência } \\
\text { do processo de } \\
\text { gestão aos preceitos } \\
\text { conceituados na } \\
\text { literatura. }\end{array}$ & $\begin{array}{l}\text { Welsh (1983) } \\
\text { Catelli (1999) }\end{array}$ \\
\hline 2 & $\begin{array}{l}\text { A criação de novos processos na } \\
\text { empresa ocorre de forma estruturada e } \\
\text { por projetos e equipes multifuncionais }\end{array}$ & $\begin{array}{c}\text { Visão } \\
\text { sistêmica }\end{array}$ & $\begin{array}{l}\text { Verificar a aderência } \\
\text { do processo de } \\
\text { gestão aos preceitos } \\
\text { conceituados na } \\
\text { literatura. } \\
\end{array}$ & $\begin{array}{l}\text { Parisi (1999) } \\
\text { Radnor e } \\
\text { Barnes (2007) }\end{array}$ \\
\hline 3 & $\begin{array}{c}\text { A característica que define a estratégia } \\
\text { formulada pela empresa é baseada em } \\
\text { um conjunto de regras que orienta as } \\
\text { decisões sobre oportunidade de } \\
\text { negócios }\end{array}$ & $\begin{array}{l}\text { Ambiente/est } \\
\text { rutu-ração do } \\
\text { processo de } \\
\text { gestão }\end{array}$ & $\begin{array}{l}\text { Verificar a aderência } \\
\text { do processo de } \\
\text { gestão aos preceitos } \\
\text { conceituados na } \\
\text { literatura. }\end{array}$ & $\begin{array}{l}\text { Parisi (1999) } \\
\text { Guerreiro } \\
(1989)\end{array}$ \\
\hline 4 & $\begin{array}{c}\text { Os administradores da empresa } \\
\text { adotam uma postura empreendedora e } \\
\text { são integrados com as diversas áreas } \\
\text { da organização }\end{array}$ & $\begin{array}{l}\text { Integração } \\
\text { entre áreas }\end{array}$ & $\begin{array}{l}\text { Verificar a aderência } \\
\text { do processo de } \\
\text { gestão aos preceitos } \\
\text { conceituados na } \\
\text { literatura. }\end{array}$ & $\begin{array}{l}\text { Parisi (1999) } \\
\text { Radnor e } \\
\text { Barnes (2007) }\end{array}$ \\
\hline 5 & $\begin{array}{l}\text { Os gerentes de loja têm autonomia } \\
\text { para tomar decisões na busca de } \\
\text { excelência do atendimento ao cliente }\end{array}$ & $\begin{array}{l}\text { Papéis e } \\
\text { postura }\end{array}$ & $\begin{array}{l}\text { Verificar a aderência } \\
\text { do processo de } \\
\text { gestão aos preceitos } \\
\text { conceituados na } \\
\text { literatura. }\end{array}$ & $\begin{array}{l}\text { Parisi (1999) } \\
\text { Kaplan e } \\
\text { Norton (2006) }\end{array}$ \\
\hline
\end{tabular}




\section{A percepção dos gestores sobre as práticas do modelo de gestão e do processo de gestão: um estudo em uma empresa varejista brasileira Claudio Parisi, Maria de Gracia Lopez Martin, Evandir Megliorini, Auster Moreira Nascimento}

\begin{tabular}{|c|c|c|c|c|}
\hline 6 & $\begin{array}{c}\text { Os gestores da empresa tomam } \\
\text { decisões estratégicas com base em } \\
\text { informações sobre mudanças ocorridas } \\
\text { no ambiente externo, com foco nas } \\
\text { mudanças e oportunidades }\end{array}$ & $\begin{array}{l}\text { Ambiente/est } \\
\text { rutu-ração do } \\
\text { processo de } \\
\text { gestão. }\end{array}$ & $\begin{array}{l}\text { Verificar a aderência } \\
\text { do processo de } \\
\text { gestão aos preceitos } \\
\text { conceituados na } \\
\text { literatura. }\end{array}$ & $\begin{array}{c}\text { Guerreiro } \\
\text { (1989) } \\
\text { Parisi }(1999)\end{array}$ \\
\hline 7 & $\begin{array}{l}\text { Todas as áreas da empresa trabalham } \\
\text { de forma integrada, inclusive a loja }\end{array}$ & $\begin{array}{l}\text { Integração } \\
\text { entre as } \\
\text { áreas }\end{array}$ & $\begin{array}{l}\text { Verificar a aderência } \\
\text { do processo de } \\
\text { gestão aos preceitos } \\
\text { conceituados na } \\
\text { literatura. }\end{array}$ & $\begin{array}{c}\text { Guerreiro } \\
(1989) \\
\text { Parisi (1999) } \\
\text { Radnor e } \\
\text { Barnes (2007) }\end{array}$ \\
\hline 8 & $\begin{array}{c}\text { Existe um adequado alinhamento entre } \\
\text { as decisões tomadas nas diversas } \\
\text { áreas da empresa com a área de } \\
\text { operações }\end{array}$ & $\begin{array}{l}\text { Integração } \\
\text { entre as } \\
\text { áreas }\end{array}$ & $\begin{array}{l}\text { Verificar a aderência } \\
\text { do processo de } \\
\text { gestão aos preceitos } \\
\text { conceituados na } \\
\text { literatura. }\end{array}$ & $\begin{array}{l}\text { Guerreiro } \\
(1989) \\
\text { Parisi (1999) } \\
\text { Kaplan e } \\
\text { Norton, (2006) }\end{array}$ \\
\hline 9 & $\begin{array}{l}\text { O processo de tomada de decisão é } \\
\text { participativo, focando a evolução do } \\
\text { mercado, necessidade dos clientes e } \\
\text { mudanças no ambiente de negócios }\end{array}$ & $\begin{array}{l}\text { Descentraliz } \\
\text { ação }\end{array}$ & $\begin{array}{c}\text { Verificar a } \\
\text { percepção de } \\
\text { gestores sobre } \\
\text { gestão de } \\
\text { desempenho em } \\
\text { busca de vantagem } \\
\text { competitiva. }\end{array}$ & $\begin{array}{l}\text { Parisi (1999) } \\
\text { Jorgensen } \\
\text { (2002) }\end{array}$ \\
\hline 10 & $\begin{array}{l}\text { Todos os colaboradores entendem e } \\
\text { praticam a missão da empresa }\end{array}$ & $\begin{array}{l}\text { Comportame } \\
\text { nto requerido }\end{array}$ & $\begin{array}{l}\text { Verificar a aderência } \\
\text { do processo de } \\
\text { gestão aos preceitos } \\
\text { conceituados na } \\
\text { literatura. }\end{array}$ & $\begin{array}{l}\text { Rossi Júnior } \\
\text { (2004) } \\
\text { Rodriguez } \\
\text { (2002) }\end{array}$ \\
\hline 11 & $\begin{array}{l}\text { As metas financeiras de longo prazo; a } \\
\text { imagem da organização; a oferta de } \\
\text { produtos e serviços; e, o aprendizado; } \\
\text { são perspectivas que, na empresa, são } \\
\text { analisadas em um mesmo contexto }\end{array}$ & $\begin{array}{l}\text { Planejament } \\
\text { o estratégico }\end{array}$ & $\begin{array}{l}\text { Verificar a aderência } \\
\text { do processo de } \\
\text { gestão aos preceitos } \\
\text { conceituados na } \\
\text { literatura. }\end{array}$ & $\begin{array}{c}\text { Kaplan e } \\
\text { Norton (1997) } \\
\text { Radnor e } \\
\text { Barnes (2007) }\end{array}$ \\
\hline 12 & $\begin{array}{c}\text { O planejamento empresarial } \\
\text { implementa a estratégia da empresa, } \\
\text { relacionando-a com o seu ambiente } \\
\text { externo, identificando ameaças e } \\
\text { oportunidades }\end{array}$ & $\begin{array}{l}\text { Planejament } \\
\text { o estratégico }\end{array}$ & $\begin{array}{l}\text { Verificar a aderência } \\
\text { do processo de } \\
\text { gestão aos preceitos } \\
\text { conceituados na } \\
\text { literatura. }\end{array}$ & $\begin{array}{c}\text { Kaplan e } \\
\text { Norton (1997) } \\
\text { Mosimann e } \\
\text { Fisch (1999) }\end{array}$ \\
\hline 13 & $\begin{array}{c}\text { A adoção de visão sistêmica, aliada à } \\
\text { visão estratégica, favorece o alcance } \\
\text { dos objetivos e metas definidos pela } \\
\text { empresa }\end{array}$ & $\begin{array}{l}\text { Visão } \\
\text { sistêmica }\end{array}$ & $\begin{array}{l}\text { Verificar a aderência } \\
\text { do processo de } \\
\text { gestão aos preceitos } \\
\text { conceituados na } \\
\text { literatura. }\end{array}$ & $\begin{array}{l}\text { Catelli (1999) } \\
\text { Kaplan e } \\
\text { Norton (1997) }\end{array}$ \\
\hline 14 & $\begin{array}{c}\text { A empresa possui um sistema de apoio } \\
\text { aos gestores para a avaliação da } \\
\text { evolução da organização }\end{array}$ & $\begin{array}{l}\text { Visão } \\
\text { sistêmica }\end{array}$ & $\begin{array}{l}\text { Verificar a aderência } \\
\text { do processo de } \\
\text { gestão aos preceitos } \\
\text { conceituados na } \\
\text { literatura. }\end{array}$ & $\begin{array}{c}\text { Guerreiro } \\
(1989) \\
\text { Kaplan e } \\
\text { Norton (1997) }\end{array}$ \\
\hline
\end{tabular}

Quadro 2 - Assertivas, variáveis-chave, objetivos e autores Fonte: Elaborado pelos autores 
A percepção dos gestores sobre as práticas do modelo de gestão e do processo de gestão: um
estudo em uma empresa varejista brasileira
Claudio Parisi, Maria de Gracia Lopez Martin, Evandir Megliorini, Auster Moreira Nascimento

\section{ANÁLISE DOS DADOS}

A seguir, na tabela 1, constam as respostas das assertivas sobre a percepção dos gestores quanto ao processo de gestão utilizado pela empresa.

Tabela 1 - Percepção dos gestores

\begin{tabular}{|c|c|c|c|c|c|c|c|}
\hline & \multirow{2}{*}{ Assertivas } & \multicolumn{6}{|c|}{ Respostas das Alternativas/Mediana } \\
\hline & & NS & 1 & 2 & 3 & 4 & MD \\
\hline \multirow{2}{*}{1} & \multirow{2}{*}{$\begin{array}{l}\text { A empresa trabalha de forma interdependente para o } \\
\text { alcance de seus objetivos. }\end{array}$} & 0 & 0 & 5 & 8 & 3 & \multirow{2}{*}{3} \\
\hline & & $0 \%$ & $0 \%$ & $\begin{array}{l}31 \\
\% \\
\end{array}$ & $50 \%$ & $\begin{array}{l}19 \\
\% \\
\end{array}$ & \\
\hline \multirow[b]{2}{*}{2} & \multirow{2}{*}{$\begin{array}{l}\text { A criação de novos processos na empresa ocorre de } \\
\text { forma estruturada e desdobrados por projetos e equipes } \\
\text { multifuncionais. }\end{array}$} & 0 & 1 & 4 & 7 & 4 & \multirow{2}{*}{3} \\
\hline & & $0 \%$ & $6 \%$ & $\begin{array}{l}25 \\
\%\end{array}$ & $44 \%$ & $\begin{array}{l}25 \\
\%\end{array}$ & \\
\hline \multirow{2}{*}{3} & \multirow{2}{*}{$\begin{array}{l}\text { A característica que define a estratégia formulada pela } \\
\text { empresa é baseada em um conjunto de regras que } \\
\text { orientam as decisões sobre oportunidade de negócios. }\end{array}$} & 0 & 0 & 2 & 12 & 2 & \multirow[t]{2}{*}{3} \\
\hline & & $0 \%$ & $0 \%$ & $\begin{array}{l}12 \\
0 /\end{array}$ & $76 \%$ & $\begin{array}{l}12 \\
0 /\end{array}$ & \\
\hline \multirow[b]{2}{*}{4} & \multirow{2}{*}{$\begin{array}{c}\text { Os administradores da empresa adotam uma postura } \\
\text { empreendedora e são integrados com as diversas áreas } \\
\text { da organização }\end{array}$} & 0 & 0 & 2 & 7 & 7 & \multirow[b]{2}{*}{3} \\
\hline & & $0 \%$ & $0 \%$ & $\begin{array}{l}12 \\
\%\end{array}$ & $44 \%$ & $\begin{array}{l}44 \\
\%\end{array}$ & \\
\hline \multirow{2}{*}{5} & \multirow{2}{*}{$\begin{array}{l}\text { Os gerentes de loja têm autonomia para tomar decisões } \\
\text { na busca de excelência do atendimento ao cliente. }\end{array}$} & 0 & 0 & 6 & 8 & 2 & \multirow{2}{*}{3} \\
\hline & & $0 \%$ & $0 \%$ & 38 & $50 \%$ & 12 & \\
\hline \multirow[b]{2}{*}{6} & \multirow{2}{*}{$\begin{array}{c}\text { Os gestores da empresa tomam decisões estratégicas } \\
\text { com base em informações sobre mudanças ocorridas no } \\
\text { ambiente externo, com foco nas ameaças e } \\
\text { oportunidades. }\end{array}$} & 0 & 1 & 2 & 10 & 3 & \multirow[b]{2}{*}{3} \\
\hline & & $0 \%$ & $6 \%$ & $\begin{array}{l}12 \\
\%\end{array}$ & $63 \%$ & $\begin{array}{l}19 \\
\%\end{array}$ & \\
\hline \multirow{2}{*}{7} & \multirow{2}{*}{$\begin{array}{l}\text { Todas as áreas da empresa trabalham de forma } \\
\text { integrada, inclusive aquelas inerentes às lojas. }\end{array}$} & 0 & 0 & 7 & 9 & 0 & \multirow{2}{*}{3} \\
\hline & & $0 \%$ & $0 \%$ & 44 & $56 \%$ & $0 \%$ & \\
\hline \multirow{2}{*}{8} & \multirow{2}{*}{$\begin{array}{c}\text { Existe um adequado alinhamento entre as decisões } \\
\text { tomadas nas diversas áreas da empresa com a área de } \\
\text { operações. }\end{array}$} & 0 & 2 & 8 & 6 & 0 & \multirow[t]{2}{*}{2} \\
\hline & & $0 \%$ & $12 \%$ & $\begin{array}{l}50 \\
0 /\end{array}$ & $38 \%$ & $0 \%$ & \\
\hline \multirow[t]{2}{*}{9} & \multirow{2}{*}{$\begin{array}{l}\text { O processo de tomada de decisão é participativo, } \\
\text { focando a evolução do mercado, necessidade dos } \\
\text { clientes e mudanças no ambiente de negócios. }\end{array}$} & 0 & 0 & 5 & 10 & 1 & \multirow[t]{2}{*}{3} \\
\hline & & $0 \%$ & $0 \%$ & 31 & $63 \%$ & $6 \%$ & \\
\hline \multirow{2}{*}{10} & \multirow{2}{*}{$\begin{array}{l}\text { Todos os colaboradores entendem e praticam a missão } \\
\text { da empresa. }\end{array}$} & 0 & 0 & 5 & 10 & 1 & \multirow[t]{2}{*}{3} \\
\hline & & $0 \%$ & $0 \%$ & $\begin{array}{l}31 \\
0 / 1\end{array}$ & $63 \%$ & $6 \%$ & \\
\hline 11 & As metas financeiras de longo prazo; a imagem da & 2 & 0 & 3 & 10 & 1 & 3 \\
\hline
\end{tabular}


A percepção dos gestores sobre as práticas do modelo de gestão e do processo de gestão: um estudo em uma empresa varejista brasileira Claudio Parisi, Maria de Gracia Lopez Martin, Evandir Megliorini, Auster Moreira Nascimento

\begin{tabular}{|c|c|c|c|c|c|c|c|}
\hline & $\begin{array}{l}\text { organização; a oferta de produtos e serviços; e o } \\
\text { aprendizado; são perspectivas que devem ser } \\
\text { analisadas dentro de um mesmo contexto. }\end{array}$ & $\begin{array}{l}12 \\
\%\end{array}$ & $0 \%$ & $\begin{array}{l}19 \\
\%\end{array}$ & $63 \%$ & $6 \%$ & \\
\hline \multirow[b]{2}{*}{12} & \multirow{2}{*}{$\begin{array}{l}\text { O planejamento empresarial implementa a estratégia da } \\
\text { empresa, relacionando-o com o seu ambiente externo, } \\
\text { identificando ameaças e oportunidades. }\end{array}$} & 0 & 0 & 1 & 12 & 3 & \multirow[b]{2}{*}{3} \\
\hline & & $0 \%$ & $0 \%$ & $6 \%$ & $75 \%$ & $\begin{array}{l}19 \\
\%\end{array}$ & \\
\hline \multirow[b]{2}{*}{13} & \multirow{2}{*}{$\begin{array}{l}\text { A adoção de visão sistêmica, aliada à visão estratégica, } \\
\text { favorece o alcance dos objetivos e metas definidos pela } \\
\text { administração da empresa. }\end{array}$} & 0 & 0 & 0 & 10 & 6 & \multirow[b]{2}{*}{3} \\
\hline & & $0 \%$ & $0 \%$ & $0 \%$ & $62 \%$ & $\begin{array}{l}38 \\
\%\end{array}$ & \\
\hline \multirow{2}{*}{14} & \multirow{2}{*}{$\begin{array}{c}\text { A empresa possui um sistema de apoio aos gestores } \\
\text { para a avaliação de sua evolução }\end{array}$} & 0 & 0 & 3 & 10 & 3 & \multirow{2}{*}{3} \\
\hline & & $0 \%$ & $0 \%$ & $\begin{array}{l}19 \\
\%\end{array}$ & $62 \%$ & $\begin{array}{l}19 \\
\%\end{array}$ & \\
\hline
\end{tabular}

$$
\begin{gathered}
\mathrm{NS}=\text { não sabe/desconhece } \\
\text { MD=Mediana }
\end{gathered}
$$

Conforme as respostas (tabela 1), constata-se que todos os entrevistados concordaram que a adoção de uma visão sistêmica, aliada à visão estratégica, favorece 0 alcance dos objetivos e das metas definidos pela empresa (assertiva 13).

Além disso, verifica -se que $94 \%$ concordaram que o planejamento empresarial é exitoso no que tange a implementar a estratégia da empresa, relacionando-a com o seu ambiente externo, identificando ameaças e oportunidades (assertiva 12), e 88\% afirmaram que a característica que define a estratégia formulada pela empresa é baseada em um conjunto de regras que orientam as decisões sobre oportunidade de negócios (assertiva 3). Ademais, na ocasião em que essa pesquisa foi realizada, os administradores da empresa adotavam uma postura empreendedora e atuavam de forma integrada com as diversas áreas da organização (assertiva 4).

Nessas assertivas, as respostas alinharam-se ao pensamento de Parisi (1999), quando esse autor descreve o modelo de gestão econômica e aponta os novos paradigmas da gestão empresarial, indicando, entre outros, os seguintes aspectos: processo decisório descentralizado, funções e responsabilidades decorrentes da missão (da empresa e da área específica do gestor) e estilo participativo (busca integração).

Observa-se também que $82 \%$ dos entrevistados concordaram que os gestores 
A percepção dos gestores sobre as práticas do modelo de gestão e do processo de gestão: um estudo em uma empresa varejista brasileira Claudio Parisi, Maria de Gracia Lopez Martin, Evandir Megliorini, Auster Moreira Nascimento

da empresa tomam decisões estratégicas com base em informações sobre mudanças ocorridas no ambiente externo, com foco nas ameaças e oportunidades (assertiva 6), e $81 \%$ concordaram que a empresa possui um sistema de apoio aos gestores na avaliação da evolução da organização (assertiva 14) mostrando alinhamento em relação aos objetivos a serem observados pelo modelo de gestão, conforme Guerreiro (1989).

As respostas às assertivas também refletiram o pensamento de Nakagawa (2003, p. 38), quando esse autor afirma que "dessa forma, o planejamento estratégico pode ser visto como uma técnica por meio da qual é determinada a atitude ou a posição estratégica da empresa", e, o de Mosimann e Fisch (1999), ao ressaltarem que "o planejamento empresarial implementa a estratégia da empresa, relacionando-o com o seu ambiente externo, identificando ameaças e oportunidades".

Da mesma forma, $69 \%$ dos entrevistados concordaram que a empresa trabalha de forma interdependente para o alcance dos objetivos (assertiva 1) e que a criação de novos processos ocorre de forma estruturada, e de forma desdobrada por projetos e equipes multifuncionais (assertiva 2) e, ainda, que o processo de tomada de decisão é participativo, focando a evolução do mercado, necessidade dos clientes e mudanças no ambiente de negócios (assertiva 9); que todos os colaboradores entendem e praticam a missão da empresa (assertiva 10) e que as metas financeiras de longo prazo; a imagem da organização, a oferta de produtos e serviços e o aprendizado, são perspectivas que devem ser analisadas dentro de um mesmo contexto (assertiva 11).

Verificou-se que $69 \%$ dos entrevistados (assertiva 10) corroboraram com a visão de Rossi Júnior (2004), quando o autor afirma que todos os envolvidos na declaração da missão devem se comprometer efetivamente com o futuro da organização.

Além disso, $62 \%$ dos entrevistados concordaram que os gerentes de loja tinham autonomia para tomarem decisões na busca de excelência do atendimento ao cliente (assertiva 5). No entanto, não existia um adequado alinhamento entre as decisões tomadas nas diversas áreas da empresa com a área de operações (assertiva 8), enquanto apenas $56 \%$ acreditavam que todas as áreas da empresa trabalhavam de 
A percepção dos gestores sobre as práticas do modelo de gestão e do processo de gestão: um estudo em uma empresa varejista brasileira Claudio Parisi, Maria de Gracia Lopez Martin, Evandir Megliorini, Auster Moreira Nascimento

forma integrada, inclusive as lojas (assertiva 7). Considera-se ser pequena a efetividade do processo de gestão em gerar sinergias, integrando as ações das diversas áreas da empresa e orientando-a para otimização de desempenho (PARISI, 1999).

Nesse contexto, cabe destacar que o índice de discordância de $38 \%$ na percepção dos respondentes sobre a autonomia dos gerentes de loja para tomada de decisões é uma questão preocupante em relação à consolidação do modelo de gestão descentralizado, levantando dúvidas sobre até que ponto o processo de gestão implantado poderia ter colaborado ou não com a questão da delegação de autonomia e descentralização de poder ou simplesmente se adequado à realidade preexistente na organização, não contribuindo com a transformação do modelo de gestão, inversamente, gerando novas tensões (FRITZ, (1997).

Merece destaque, também, em nível organizacional, o índice de discordância de $62 \%$ na percepção dos respondentes sobre o alinhamento entre as decisões tomadas nas diversas áreas da empresa com a área de operações. Considerando os preceitos de Kaplan e Norton (2006) sobre o desdobramento do BSC, e que a empresa é usuária dessa abordagem, infere-se que o desdobramento do BSC corporativo para as áreas pode ter sido feito parcialmente (só as unidades fins) ou de forma equivocada, gerando esse desalinhamento.

Outros resultados reforçam essa preocupação em nível organizacional. Trata-se do índice de $31 \%$ de discordância na percepção dos respondentes sobre a assertiva 1 A empresa trabalha de forma interdependente para o alcance dos objetivos e, de $44 \%$ de discordância na assertiva 7 - Todas as áreas da empresa trabalham de forma integrada, inclusive as lojas.

Tais resultados indicam que o modelo de gestão e o processo de gestão de desempenho podem não ter sido totalmente institucionalizados na empresa, pois os propósitos indicados nas assertivas 1, 5, 7 e 8 não foram percebidos por todos os respondentes. 
A percepção dos gestores sobre as práticas do modelo de gestão e do processo de gestão: um estudo em uma empresa varejista brasileira Claudio Parisi, Maria de Gracia Lopez Martin, Evandir Megliorini, Auster Moreira Nascimento

\section{CONCLUSÃO}

O objetivo dessa pesquisa foi o de conhecer se as percepções dos gestores integrantes do grupo de planejamento sobre as práticas de gestão envolvendo o modelo de gestão e o processo de gestão são aderentes aos preceitos abordados na literatura existente sobre esse tema e que foi usada no suporte à teorização durante a fase de implantação da solução. Observa-se pelas respostas que na percepção dos gestores ainda alguns aspectos, tanto relacionados ao modelo de gestão como ao processo de gestão, não têm nas suas práticas aderência aos conceitos referenciados pela literatura, particularmente aqueles relacionados à descentralização e autonomia das lojas (modelo de gestão), integração e alinhamento das decisões (processo de gestão).

Conclui-se que as possíveis falhas do processo de gestão que geravam desalinhamento das decisões entre as diversas áreas, e a percepção de baixo nível de integração entre estas, podem ter sido fruto da dificuldade em se descentralizar as decisões na organização, em decorrência da prevalência da característica do poder inerente ao modelo de gestão anterior, concentrado na alta administração, que permaneceram inalteradas.

Quanto ao problema de pesquisa: segundo a percepção dos gestores, as práticas decorrentes do modelo de gestão e do processo de gestão implantados pela empresa varejista são aderentes aos preceitos conceituados na literatura? Os resultados apontam para a aderência parcial das práticas do modelo de gestão e do processo de gestão existentes na empresa em relação aos preceitos preconizados na literatura.

Entende-se que o estudo contribui com o debate sobre a gestão de desempenho da empresa, descrevendo a percepção dos gestores sobre o uso de instrumentos gerenciais propostos pela academia, evidenciando os seus pontos de aderência e de afastamento entre o que é proposto pela literatura e o que efetivamente a empresa conseguiu praticar. Também o estudo contribui com a investigação sobre a integração 
A percepção dos gestores sobre as práticas do modelo de gestão e do processo de gestão: um estudo em uma empresa varejista brasileira Claudio Parisi, Maria de Gracia Lopez Martin, Evandir Megliorini, Auster Moreira Nascimento

de diferentes abordagens de instrumentos gerenciais para a revisão de modelos de gestão e a estruturação de processos de gestão.

Por fim, sugere-se investigar em pesquisas futuras os desafios na transformação de modelos de gestão no contexto da implantação e uso de instrumentos de Controladoria e o quanto a estruturação do processo de gestão contribui com a formalização do processo de decisório nas organizações.

\section{REFERÊNCIAS}

CAMARGOS, D. (2008). Advent compra rede gaúcha. Revista Exame.Texto disponível em: < http://portalexame.abril.com.br/degustacao/secure/degustacao.do?COD_SITE=35\&C OD_RECURSO=211\&URL_RETORNO=http://portalexame.abril.com.br/negocios $/ \mathrm{m} 016$ 7350.html . Acesso em 3/nov/2008.

Catelli, A. (1999). Controladoria: uma abordagem da gestão econômica GECON. São Paulo: Atlas.

CATELLI, A.; GUERREIRO, R.; PEREIRA, C. A.; ALMEIDA, L. B. (1999). Sistema de Gestão Econômica - GECON. In: Catelli, A. Controladoria: uma abordagem da gestão econômica GECON. São Paulo: Atlas.

CATELLI, A.; PEREIRA, C. A.; VASCONCELOS, M. T. C. (1999). Processo de Gestão e Sistema de Informações Gerenciais. In Catelli, A. Controladoria: uma abordagem da gestão econômica GECON. São Paulo: Atlas.

COOPER, D.R.; SCHINDLER, P.S. (2003). Métodos de Pesquisa em Administração. (7 ed.). Porto Alegre: Bookman.

CORRAR, L. J.; THEOPHILO, C. R. (2004). Pesquisa operacional para decisão em contabilidade e administração. São Paulo: Atlas.

COSTA, A.J.D.; GARCIA, J.R. (2006). O empresário schumpeteriano e o setor de varejo no Brasil: Samuel Klein e as Casas Bahia. Revista de Economia, v. 32, n.1, ano 30, p. 57-82, jan./jun. Editora UFPR.

CRUZ, R.I. (1991). Uma contribuição à definição de um modelo conceitual para a gestão econômica. (Dissertação de Mestrado). FEA. São Paulo: Universidade de São Paulo. 
A percepção dos gestores sobre as práticas do modelo de gestão e do processo de gestão: um estudo em uma empresa varejista brasileira Claudio Parisi, Maria de Gracia Lopez Martin, Evandir Megliorini, Auster Moreira Nascimento

DeBusk, G. K; Crabtree, A. D. (2006). Does the Balanced Scorecard Improve Performance? Management Accounting Quarterly, Fall, vol. 8, no. 1.

ELY, E. E. (2001). Profissionalização do varejo: uma questão de sobrevivência. Texto disponível em: <http://www.varejista.com.br/novo_site/desc_materia.asp?id=136. Acesso em 3/nov/2008>.

GIL, A. C. (2002). Métodos e técnicas de pesquisa social. São Paulo: Atlas.

GIULIANI, A.C. et al. (2004). Processo empreendedor: o caso de um centro de compras. XXIV ENCONTRO NAC. DE ENG. DE PRODUÇÃO. Florianópolis, SC, Brasil, 03 a 05 de nov.

GUERREIRO, R. (1989). Modelo conceitual de sistema de informação de gestão econômica: uma contribuição à teoria da comunicação da contabilidade. (Tese de Doutorado). FEA. São Paulo: Universidade de São Paulo.

HILL, M. M; HILL, A. (2002). Investigação por questionário. Lisboa: Sílabo.

INSTITUTO PARA O DESENVOLVIMENTO DO VAREJO (IDV). Panorama do varejo antes da crise. 18/11/2008. Texto disponível em: $<$ http://www.idv.org.br/conjuntura-ccv-texto.aspx? IdTextoCCV=384>. Acesso em 2/nov/2008.

JORGENSEN, B. Borealis. (2002). Harvard Business School, 9-102-048, Maio.

KAPLAN, R. S., NORTON, D. P. (1992). The Balanced Scorecard - measures that drive performance. Harvard Business Review, vol. 70, Janeiro/fevereiro.

Campus. . (1997). A estratégia em ação - Balanced scorecard. (10 ed.). Rio de Janeiro. . (2006). Alinhamento: usando o Balanced Scorecard para criar sinergias corporativas. Rio de Janeiro. Campus.

KOTLER, P. (2000). Administração de Marketing: análise, planejamento, implementação e controle. (10 ed.). São Paulo: Atlas.

MANÃS, A.V.; PACANHAM, M.N. (2004). Alianças estratégicas e redes associativas como fonte de vantagem competitiva no varejo de material de construção. Revista Brasileira de Negócios - FECAP, ano 6 no 14, abr.

McNAIR, C. J. e WATTS, T. (2009). The Integration of Balanced Scorecard Models. Cost Management, 23,5, Setembro/Outubro. 
A percepção dos gestores sobre as práticas do modelo de gestão e do processo de gestão: um estudo em uma empresa varejista brasileira

Claudio Parisi, Maria de Gracia Lopez Martin, Evandir Megliorini, Auster Moreira Nascimento

MOSIMANN, C. P.; FISCH, S. (1999). Controladoria: seu papel na administração de empresas. São Paulo: Atlas.

NAKAGAWA, J. (2003). Sistema de segmentação de clientes pessoas físicas de um banco fundamentado no modelo GECON. 138 fls. (Dissertação de Mestrado). Universidade Federal de Santa Catarina. Florianópolis.

PARENTE, J. (2000). Varejo no Brasil: gestão e estratégia. São Paulo: Atlas.

PARISI, C. (1999). Ensaio sobre o comportamento organizacional. In Catelli, A. Controladoria: uma abordagem da gestão econômica GECON. São Paulo: Atlas.

RADNOR, Z. J.; BARNES, D. (2007). Historical analysis of performance measurement and management in operations management. International Journal of Productivity and Performance Management, Vol. 56 No. 5/6, pp. 384-396

RODRIGUEZ, M. V. R. (2002). Gestão empresarial: organizações que aprendem. Rio de Janeiro, Qualitymark: Petrobrás.

ROSSI JÚNOR, L.R. (2004). A gestão para resultados como ferramenta administrativa nas organizações do terceiro setor. Revista Integração/FGV. Disponível em: http://integracao.fgvsp.br/ano4/2/administrando.htm. Acesso em: 2/nov/2008.

TATIKONDA, L. V.; TATIKONDA, R. J. (1998). We need dynamic performance measures. Management Accounting. V. 80, n. 3, p. 49-51.

WELSCH, G. A. (1983). Orçamento empresarial. 4. ed. São Paulo: Atlas.

Data de Submissão: 22/06/2011

Data de Aceite: 23/12/2011 